\title{
pnmbalina
}

(8)

\section{Dos Antígonas cubanas en el nuevo milenio}
Autor(es):
Miranda Cancela, Elina
Publicado por: Coimbra; Imprensa da Universidade de Coimbra; Imprensa da Universidade de Coimbra
Centro de Estudos Clássicos e Humanísticos da Universidade de

\author{
URL \\ persistente: \\ URI:http://hdl.handle.net/10316.2/30254 \\ DOI: \\ DOI:http://dx.doi.org/10.14195/978-989-721-038-9_35
}
Accessed : $\quad$ 26-Apr-2023 02:52:51

A navegação consulta e descarregamento dos títulos inseridos nas Bibliotecas Digitais UC Digitalis, UC Pombalina e UC Impactum, pressupõem a aceitação plena e sem reservas dos Termos e Condições de Uso destas Bibliotecas Digitais, disponíveis em https://digitalis.uc.pt/pt-pt/termos.

Conforme exposto nos referidos Termos e Condições de Uso, o descarregamento de títulos de acesso restrito requer uma licença válida de autorização devendo o utilizador aceder ao(s) documento(s) a partir de um endereço de IP da instituição detentora da supramencionada licença.

Ao utilizador é apenas permitido o descarregamento para uso pessoal, pelo que o emprego do(s) título(s) descarregado(s) para outro fim, designadamente comercial, carece de autorização do respetivo autor ou editor da obra.

Na medida em que todas as obras da UC Digitalis se encontram protegidas pelo Código do Direito de Autor e Direitos Conexos e demais legislação aplicável, toda a cópia, parcial ou total, deste documento, nos casos em que é legalmente admitida, deverá conter ou fazer-se acompanhar por este aviso.

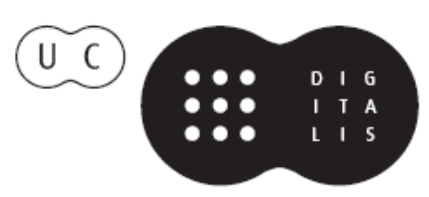




\section{De ayer a hoy}

\section{Influencias clásicas en la literatura}

\section{Aurora López, Andrés Pociña, Maria de Fátima Silva (coords.)}




\section{Dos Antígonas cubanas en el nuevo milenio}

Elina Miranda Cancela Universidad de La Habana

Aunque en 1941 la puesta en escena de Antígona de Sófocles funda Teatro Universitario, y en alguna medida marca la presencia de mitos clásicos en el teatro cubano de la segunda mitad del siglo XX, a diferencia de lo que acontece con Electra o Medea, por ejemplo, sólo en los primeros años de la década de los '90 este mito clásico motiva una versión de autor cubano publicada o representada en el país. A partir de fines de siglo y sobre todo en la primera década de este milenio, los mitos clásicos sirven de punto de partida de un número relativamente grande a piezas de autores cubanos de distintas generaciones, entre ellas dos que retoman la tragedia sofoclea de la hija de Edipo: Antígona, de Reinaldo Montero, estrenada en 2010, pero escrita desde 2006 y con una lectura dramatizada en 2009, y la también titulada con sólo el nombre de la heroína griega, Antígona, del joven dramaturgo Yerandy Fleites, publicada en 2007 por la revista Tablas. Nos proponemos, por tanto, en nuestra exposición, estudiar comparativamente ambas obras y ubicarlas entre las diversas posibilidades significativas que esta figura del teatro griego ha recibido en el teatro de las Anrillas Mayores.

Antígona, a partir de su plasmación como heroína trágica en la obra de Sófocles, ha sido probablemente una de las figuras míticas que más relecturas ha suscitado en el teatro moderno, así como estudios significativos dentro del área de la filología y la tradición clásicas. Su resonancia en tierras de Nuestra América, según acuñara José Martí, ha quedado demostrada recientemente en la tesis de Rómulo Pianacci titulada precisamente Antígona, una tragedia latinoamericana ${ }^{1}$.

Sin embargo, su presencia en versiones representadas o publicadas en Cuba es relativamente tardía, no obstante haber sido este país el primero de las tres Antillas Mayores en que se produjo, en 1941, una puesta en escena del texto de Sófocles, bajo la dirección de Ludwig Shajowicz. Saludada por intelectuales y escritores de la talla de Alejo Carpentier, actuó como acta de fundación de Teatro Universitario, así como de un seminario en que se formaría toda una generación de directores y actores, al tiempo que contribuiría a que Virgilio Piñera escribiera su Electra Garrigó, iniciadora de un teatro nacional verdaderamente contemporáneo, la cual, a su vez,

\footnotetext{
${ }^{1}$ Publicada en Irvine, Gestos, 2008.
} 
favoreció el acercamiento a los mitos y cánones griegos de otros notables dramaturgos ${ }^{2}$.

No obstante, solo a fines del siglo pasado se produce el estreno por primera vez de una versión dramatúrgica propia ${ }^{3}$, mientras que en el primer decenio de este nuevo milenio, como parte de un número relativamente notable de obras basadas en mitos clásicos ${ }^{4}$, se estrenan o editan varias versiones de la tragedia sofoclea ${ }^{5}$, de las cuales al menos dos han gozado de cierta difusión: una debida a un escritor y dramaturgo ya reconocido, Reinaldo Montero, quien en 1997 había publicado y puesto en escena su versión de la Medea de Eurípides y que termina en 2006 su Antigona, obra de la que en diciembre del 2009 se hace una lectura dramatizada y se estrena en 2010; otra, la de Yerandy Fleites, recién egresado del Instituto Superior de Arte, el cual publica en la revista Tablas, en 2007, su texto en torno al personaje sofocleo, parte de una especie de trilogía, entonces en proceso, sobre heroínas trágicas, todas adolescentes.

En su Antígona Montero no pretende un apego al texto de Sófocles semejante al mantenido con el de Eurípides en su Medea: ya no marca la alternancia de episodios y stásima; la acción se maneja libremente así como la caracterización de los personajes, de los cuales, o bien prescinde, como de Hemón, o bien amplía su papel en escena, tal como acontece con Eurídice y Tiresias; pero utiliza el mismo juego metateatral en que los personajes son conscientes de la tradición en que se inscriben, al tiempo que procura un tono elevado, a veces poético, aunque el diálogo se salpique por frases cotidianas.

Estructura su obra en dos partes de 11 y 10 escenas respectivamente, denominadas "La culpa" y "El castigo", inspiradas quizás en la estructura díptica de Sófocles, pero con la diferencia de que la muerte de Antígona se retarda casi hasta el final mismo de la pieza, de modo que tanto ella como Creón pueden sopesar su decisión.

Como en la obra sofoclea Antígona e Ismene se enfrentan a la muerte de

${ }^{2}$ Cf. de la autora, Calzar el coturno americano, La Habana, Ediciones Alarcos, 2006; Letras Cubanas, 2007.

${ }^{3}$ Se trata de "Antígona", pieza que el grupo Estudio Teatral de Santa Clara, dirigido por Joel Sáez, comienza a montar en el primer tercio de 1993 y estrena en 1994. Con ella el grupo gana el primer premio en el Festival de Teatro de Camagüey de ese año.

${ }^{4}$ El Estudio Teatral de Santa Clara estrenó de Joel Sáez Los Atridas en 2008 y Casandra en 2009. De Norge Espinosa se representó Icaros en 2003, así como Medea sueña Corinto, de Abelardo Estorino en 2009; se publicó de Yerandy Fleites Pérez Jardín de héroes (Editorial Abril, 2007; subió a escena en 2009), mientras que en la revista Tablas se dio a conocer en 2007 de Maikel Rodríguez de la Cruz el texto de su Medea reloaded y hay noticias sobre otras obras, algunas en proceso de edición.

${ }^{5}$ Pepe Santos, por ejemplo, hizo una representación de una obra titulada Contraantígona, en 2004, pero no se ha podido localizar el texto ni otros datos sobre esta puesta en escena de carácter limitado. También hay noticias de al menos otra más pero que no ha sido publicada ni representada. 
sus hermanos y la orden de Creón de dejar insepulto el cadáver de Polinices, pero el incesto asumido por la protagonista como acto liberador del propio miedo que la transgresión encierra, sustenta su determinación, al tiempo que se subraya la confrontación con el gobernante al cual "la muerte no le basta. Tiene que humillar" (escena 1).

No le preocupa a Tiresias el problema sexual, ello caería en la esfera de lo privado, sino cuando Creón confunde la moral con la soberbia y declara a uno hijo de la patria y a otro hijo de puta (escena 2), el Héroe y el Traidor (escena 4). Entonces sí se está en la órbita de lo público. De ahí que la actuación de Antígona, defendida siempre por esta como estrictamente personal, se convierta en conflicto público, puesto que a diferencia de Ismene, quien no estaría en desacuerdo con enterrar al hermano discretamente, reivindica su derecho a actuar sin ocultamientos.

También en esto se opone a Creón, para quien el conflicto radica en optar por ser considerado por la opinión pública un asesino o un gobernante débil. Sus excesos en el poder le proporcionan dolores de cabeza que solo alivia apelando al sexo con una Eurídice incondicional a la cual desprecia en cualquier otra faceta que no sea la de simple remedio de sus apetencias.

En época en que se impone la necesidad de redefinir límites entre lo privado y lo público sin soslayar su interrelación, la Antígona de Montero reclama una libertad de amar que no se detiene ni en el tabú del incesto, de actuar sin dobleces tanto en una esfera como en la otra. En una especie de Tebas, marcada por la presencia del mar $^{6}$, la heroína se enfrenta a los esquemas establecidos, subvierte con sus cuestionamientos las definiciones asentadas más allá de las relaciones de poder- y, a diferencia de su hermana, no acepta estereotipos ni doble moral, pero tampoco quiere ser usada por otros.

Al final, dentro de una expresa metateatralidad que devuelve a los personajes a una especie de limbo de la tradición teatral -"caprichos del autor" como afirma Tiresias desde un mundo al que no sabe cómo ha llegado-, Antígona, sombra ella misma, se aferra a la búsqueda de lo que estima su razón de ser, sin reparar en la amenaza de olvido; mientras que, entre los vivos, se mantienen los Creontes - puesto que en la obra se augura su fin, pero este queda en suspenso-, los cuales, como nuevos Midas, corrompen todo lo que tocan.

En la Antígona que Yerandy Fleites escribe aún siendo estudiante, al igual que en la de Montero, prima la ambigüedad sobre el espacio y el tiempo. "De

\footnotetext{
${ }^{6}$ Montero evoca expresamente la definición de la insularidad dada por Virgilio Piñera - "la maldita circunstancia del agua por todas partes"- en su poema "La Isla en Peso", en 1943, solo que la transforma en "bendita", por ironía pero también consciente de su opuesto, la apertura que los puertos suponen, tan presente en su Medea.
} 
esta Tebas sin Tebas", afirma su Creonte; aunque la presencia del mar, en una, $y$, en ambas, expresiones identificables en el contexto cubano, las vinculan al país de origen. La contaminación de elementos modernos - aspecto también coincidente con Montero-, pero sobre todo la misma cotidianidad de las acciones de los personajes y el uso de un lenguaje sin el tono elevado propio de la tragedia, trasladan a nuestros tiempos y a nuestras circunstancias personajes que como Antígona y Creonte no dejan de estar conscientes de su estirpe teatral.

Con José Watanabe, el poeta peruano quien en el 2000 diera a conocer una Antígona cuya puesta en escena estuviera a cargo del grupo Yuyachkani, tiene en común Fleites el interés por la figura de Ismene; pero a diferencia del primero, en quien la tragedia de los que han permanecido en silencio cobra cuerpo en la hermana de Antígona, en el cubano la actitud de plegarse a los hechos de que Sófocles la dotara como contrapunto efectivo, es sinónimo también de un modo de entender la vida, enajenada por frívolas revistas y cigarrillos, así como por una obcecada limpieza de ama de casa sin mayores perspectivas.

Es esta Ismene - mayor que su hermana, fea y enamorada sin esperanza de un Hemón, guapo pero mudo- la que abre y cierra la obra tratando de hacer entender sus razones, a manera de círculo dentro del cual quedan comprendidos los hechos que pretende reducir y asimilar con argumentos a la esfera de su cotidianidad y frustración vital.

Antígona, casi una niña, no necesita razonar su acción, como sí lo hace la heroína griega. No conocía prácticamente al hermano, pero ha sentido la necesidad de hacer algo por su cadáver insepulto. Contenta de su acción, entona una especie de canto centrado en la paradoja vivos/muertos, resorte efectivo de la ironía trágica de Sófocles. Mas su enfrentamiento principal no es con Creonte sino con Ismene, amante de la pulcritud pero con los pulmones deshechos por tanto humo de cigarrillos; mientras que ella no vacila en ensuciarse las manos al enterrar a su hermano. Quiere saber los porqués, acepta los riesgos y hace suya, como para que no quepa duda sobre su identificación, las emblemáticas palabras de su modelo ático, pero con un significativo agregado: "No nací para jugar al odio, manita, sino al amor"7.

En muchos aspectos Creonte se asemeja a Ismene y ambos entrarían en la definición de "basura" dada por esta, la cual, según afirma, mata, como pasó con $\mathrm{Edipo}^{8}$, al cual, a su vez, el tío confiesa que amaba pero también odiaba. No

\footnotetext{
${ }^{7}$ Y. Fleites, "Antígona”, en revista Tablas, 3-4, La Habana, 2007, p. XXXII. El subrayado es de la autora

8 "A nuestro padre le cayó una basurita, una simple basurita en el ojo y murió de una terrible infección por restregarse con las manos sucias. No restregarse, no moverse, no aniquilarse, no fumar. De algún modo con él murió también la humanidad". Y. Fleites, "Antígona", en: Tablas, vol. LXXXVII, La Habana, julio-diciembre 2007, p. XXIV.
} 
experimenta este Creonte ninguna peripecia ni anagnórisis y su importancia en la obra disminuye, al tiempo que es consciente de su papel en el mito9.

Por su juventud no desconfía esta Antígona de las irónicas promesas del tío. Al ser arrastrada, Antígona forcejea y muerde, como antes se había resistido a los guardias tirándoles terrones, pero no entiende muy bien a dónde la llevan. "A las bambalinas" es la respuesta de Ismene como para confinar lo heroico a los lindes teatrales. Para ella estos "no son tiempo de héroes, sino de seres vivos que necesitamos respirar"10.

La oposición principal no es, por tanto, entre vivos y muertos, ni generacional-aunque el papel de lo jóvenes sea una preocupación fundamental-, sino entre los "héroes" y la gente que acepta lo establecido, se pliega a las circunstancias, pretende una vida tranquila, sin sobresaltos, llena de pequeñeces y razonamientos justificativos, como los de la propia Ismene, en pretendida demostración de las virtudes de su propuesta. Es ella la que aparentemente triunfa; por ese algún crítico ha calificado la obra de Anti-Antígona ${ }^{11}$.

Sin embargo, la heroína de Fleites, al igual que la de Sófocles, actúa en función de lo que estima su deber, aunque tenga que desafiar lo establecido y, al final, su recuerdo deviene esperanza y reivindicación, según tiene que admitir la propia Ismene: "se ha puesto de moda", según su decir. Adquiere matices distintos, pero su acción continúa ofreciendo un paradigma y una fuente de reflexión; por tanto, sigue siendo Antígona aunque en una nueva versión.

Al igual que en la obra estrenada en 1994 por el Teatro Estudio de Santa Clara dirigido por el entones joven director Joel Sáez, en estas de la primera década de este siglo se mantiene los atuendos griegos, mas no se pretende, en ninguna de las tres, una representación arqueológica, sino establecer contrastes entre pasado y presente mediante la contaminación con otros "repertorios" culturales, en el sentido atribuido al término por Iser ${ }^{12}$. Se procura, por tanto, que el posible receptor capte la actualidad del mito y remita el conflicto no a un pasado ya superado, sino lo entienda en función de sus circunstancias, al tiempo que la heroína griega deviene emblema de inquietudes y expectativas propias.

9 "Sabes cuántos mitos circundan esta ciudad? ¿Sabes acaso tú, muchacha, la cantidad de literatura que se está haciendo ahora mismo en el mundo a costillas mías? Sí, yo soy el malo. Yo soy el malo de esta historia, y eso es un problema irremediable”. Ibid., p. XXIX

${ }^{10}$ Ibid., p. XXXII. XXIII

${ }^{11}$ Cfr. Habey Hechavarría Prado. "Anti-Antígona”, en Tablas, volumen ya citado, p. XXII-

${ }^{12}$ Se utiliza el término "repertorio" en el sentido utilizado por Wolfgang Iser de realidad extraestética que apela a un saber determinado del lector: convenciones, normas, tradiciones, contexto socio-cultural, valores de la época y hábitos de percepción que permiten la descodificación del texto. Cfr. Wolfgang Iser, El acto de leer. Teoría del efecto estético, Madrid, Taurus, 1987. 
Pero Sáez usa prácticamente las mismas palabras de las tragedias sofocleas que reestructura en función de centrarse en la historia y las motivaciones de Antígona, con su consiguiente adaptación, puesto que quiere rescatar la teatralidad, de modo que el peso recae sobre la expresividad actoral y la puesta es equivalente, en alguna medida, sobre todo por el carácter efímero del hecho teatral potenciado por este colectivo, a los performances de las artes plásticas. De ahí la imposibilidad de una publicación: la obra solo existe como puesta en escena en que, a pesar de los fracasos, Antígona proporciona un modelo de la necesidad de obrar y apostar por las utopías.

Sin embargo, tanto para Montero como para Fleites el hipotexto trágico continua siendo relevante, así como la importancia de expresar una lectura propia a través de nuevas versiones y de ahí la libertad en su tratamiento, subrayando ambos, aunque de maneras diferentes, el carácter metateatral de sus piezas, en las cuales la tradición y su transgresión resultan polos imprescindibles para entender sus objetivos y subrayar sus propuestas de relectura a la luz de conflictos e inquietudes muy actuales.

Enfrentada a la redefinición de los límites entre lo público y lo privado o a un ambiente de lugares comunes, como resguardo de frustraciones, en fin, a los estereotipos entronizados, la Antígona sofoclea con su tenaz resistencia mantiene su vigencia a las puertas de un nuevo milenio marcado con tantos cuestionamientos e incertidumbres. El diálogo transgresivo refuerza la pervivencia al tiempo que hace propios mitos y cánones clásicos. 